\title{
Perception of Executive Order on Medicare Pay for Advanced Practice Providers: A Study of Comments From Medical Professionals
}

\author{
Claire R. Stewart, BA; Shari R. Lipner, MD, PhD
}

\section{PRACTICE POINTS}

- On October 3, 2019, President Donald Trump issued the Executive Order on Protecting and Improving Medicare for Our Nation's Seniors, in which he proposed eliminating supervision requirements for advanced practice providers (APPs) and equalizing Medicare reimbursements among APPs and physicians.

- In a review of comments posted on online forums for medical professionals, a majority of medical professionals disapproved of the executive order.

- Advanced practice providers were more likely to support the plan, citing the breadth of their experience, whereas physicians were more likely to disapprove based on their extensive training within their specialty. were 155 commenters. Our study highlights physician concerns about the executive order, specifically the importance of appropriate supervision and improved dermatologic training of APPs so that patients are provided with the best possible medical care.

Cutis. 2021;107:46-50.

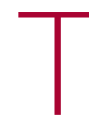

he ability of advanced practice providers (APPs) to practice independently has been a recent topic of discussion among both the medical community and legislatures. Advanced practice provider is an umbrella term that includes physician assistants (PAs) and advanced practice registered nurses, including nurse practitioners (NPs), clinical nurse specialists, certified nurse-midwives, and certified registered nurse anesthetists. Since Congress passed the Balanced Budget Act of 1997, APPs can bill and be paid independently if they are not practicing incident to a physician or in a facility. ${ }^{1}$ Currently, NPs can practice independently in 27 states and Washington, DC. Physician assistants are required to practice under the supervision of a physician; however, the extent of supervision varies by state. ${ }^{2}$ Advocates for broadening the scope of practice for APPs argue that NPs and PAs will help to fill the physician deficit, particularly in primary care and rural regions. It has been projected that by 2025, the United States will require an additional 46,000 primary care providers to meet growing medical needs. ${ }^{3}$

From Weill Cornell Medicine, New York, New York. Dr. Lipner is from the Department of Dermatology.

The authors report no conflict of interest.

The eTable is available in the Appendix online at www.mdedge.com/dermatology.

Correspondence: Shari R. Lipner, MD, PhD, Department of Dermatology, Weill Cornell Medicine, 1305 York Ave, 9th Floor, New York, NY 10021 (sh19032@med.cornell.edu).

doi:10.12788/cutis.0148 
On October 3, 2019, President Donald Trump issued the Executive Order on Protecting and Improving Medicare for Our Nation's Seniors, in which he proposed an alternative to "Medicare for all." ${ }^{4}$ This order instructed the Secretary of Health and Human Services to prepare a regulation that would "eliminate burdensome regulatory billing requirements, conditions of participation, supervision requirements, benefit definitions and all other licensure requirements ... that are more stringent than applicable Federal or State laws require and that limit professionals from practicing at the top of their field." Furthermore, President Trump proposed that "services provided by clinicians, including physicians, physician assistants, and nurse practitioners, are appropriately reimbursed in accordance with the work performed rather than the clinician's occupation."

In response to the executive order, members of the medical community utilized Reddit (https://www .reddit.com/), an online public forum, and Medscape (https://www.medscape.com), a medical news website, to vocalize opinions on the executive order. ${ }^{5,6}$ Our goal was to analyze the characteristics of those who participated in the discussion and their points of view on the plan to broaden the scope of practice and change the Medicare reimbursement plans for APPs.

\section{Methods}

All comments on the October 3, 2019, Medscape article, "Trump Executive Order Seeks Proposals on Medicare Pay for NPs, PAs, ${ }^{\prime 5}$ and the corresponding Reddit discussion on this article ${ }^{6}$ were reviewed and characterized by the type of commenter-doctor of medicine (MD)/doctor of osteopathic medicine (DO), NP/RN/certified registered nurse anesthetist, PA, medical student, PA student, NP student, pharmacist, dietician, emergency medical technician, scribe, or unknown-as identified in their username, title, or in the text of the comment. Gender of the commenter was recorded when provided. Commenters were further grouped by their support or lack of support for the executive order based on their comments. Patients' comments underwent further qualitative analysis to identify general themes.

All analyses were conducted with RStudio statistical software. Analyses were reported as proportions. Variables were compared by $\chi^{2}$ and Fisher exact tests. Odds ratios with $95 \%$ CIs were calculated. $P<.05$ was considered statistically significant.

\section{Results}

A total of 352 comments (130 on Medscape and 222 on Reddit) posted by 155 unique users (57 on Medscape and 98 on Reddit) were included in the analysis (Table 1). Of the 51 Medscape commenters who identified a gender, $60.7 \%$ were male and $39.2 \%$ were female. Reddit commenters did not identify a gender. Commenters included MD and DO physicians (43.2\%), NPs/RNs/ certified registered nurse anesthetists (13.5\%), medical students (11.0\%), PAs (9.7\%), pharmacists (3.2\%),
TABLE 1. Comment Characteristics

\begin{tabular}{|c|c|}
\hline & Comments, n (\%) \\
\hline Total comments & 352 \\
\hline Unique commenters & $155(44.0)$ \\
\hline Medscape comments & $130(36.9)$ \\
\hline Reddit comments & $222(63.1)$ \\
\hline \multicolumn{2}{|l|}{ Profession } \\
\hline MD/DO & $67(43.2)$ \\
\hline \multicolumn{2}{|c|}{$\begin{array}{l}\mathrm{NP} / \mathrm{RN} / \text { certified registered } \\
\text { nurse anesthetist }\end{array}$} \\
\hline \multicolumn{2}{|l|}{ Medical student } \\
\hline PA & $15(9.7)$ \\
\hline Pharmacist & $5(3.2)$ \\
\hline NP student & $3(1.9)$ \\
\hline PA student & $2(1.3)$ \\
\hline Emergency medical tec & $2(1.3)$ \\
\hline Dietician & $1(0.6)$ \\
\hline Scribe & $1(0.6)$ \\
\hline Unknown & $21(13.5)$ \\
\hline
\end{tabular}

Abbreviations: MD, doctor of medicine; $\mathrm{DO}$, doctor of osteopathic medicine; NP, nurse practitioner; RN, registered nurse; PA, physician assistant.

NP students (1.9\%), PA students (1.3\%), emergency medical technicians $(1.3 \%)$, dieticians $(0.6 \%)$, and scribes (0.6\%). Physicians (54.5\% vs $36.73 \% ; P=.032$ ) and NPs ( $22.8 \%$ vs $8.2 \% ; P=.009)$ made up a larger percentage of all comments on Medscape compared to Reddit, where medical students were more prevalent (16.3\% vs $1.8 \%$; $P=.005)$. Nursing students and PA students more commonly posted on Reddit (4.08\% of Reddit commenters vs $1.75 \%$ of Medscape commenters), though this difference did not achieve statistical significance.

A majority of commenters did not support the executive order, with only $20.6 \%$ approving of the plan, $54.8 \%$ disapproving, and $24.5 \%$ remaining neutral (Figure). Advanced practice providers-NPs, PAs, NP/PA students, and APPs not otherwise specified-were more likely to support the executive order, with $52.3 \%$ voicing their support compared to only $4.8 \%$ of physicians and medical students expressing support $(P<.0001)$. Similarly, physicians and medical students were more likely to disapprove of the order, with $75.0 \%$ voicing concerns compared to 


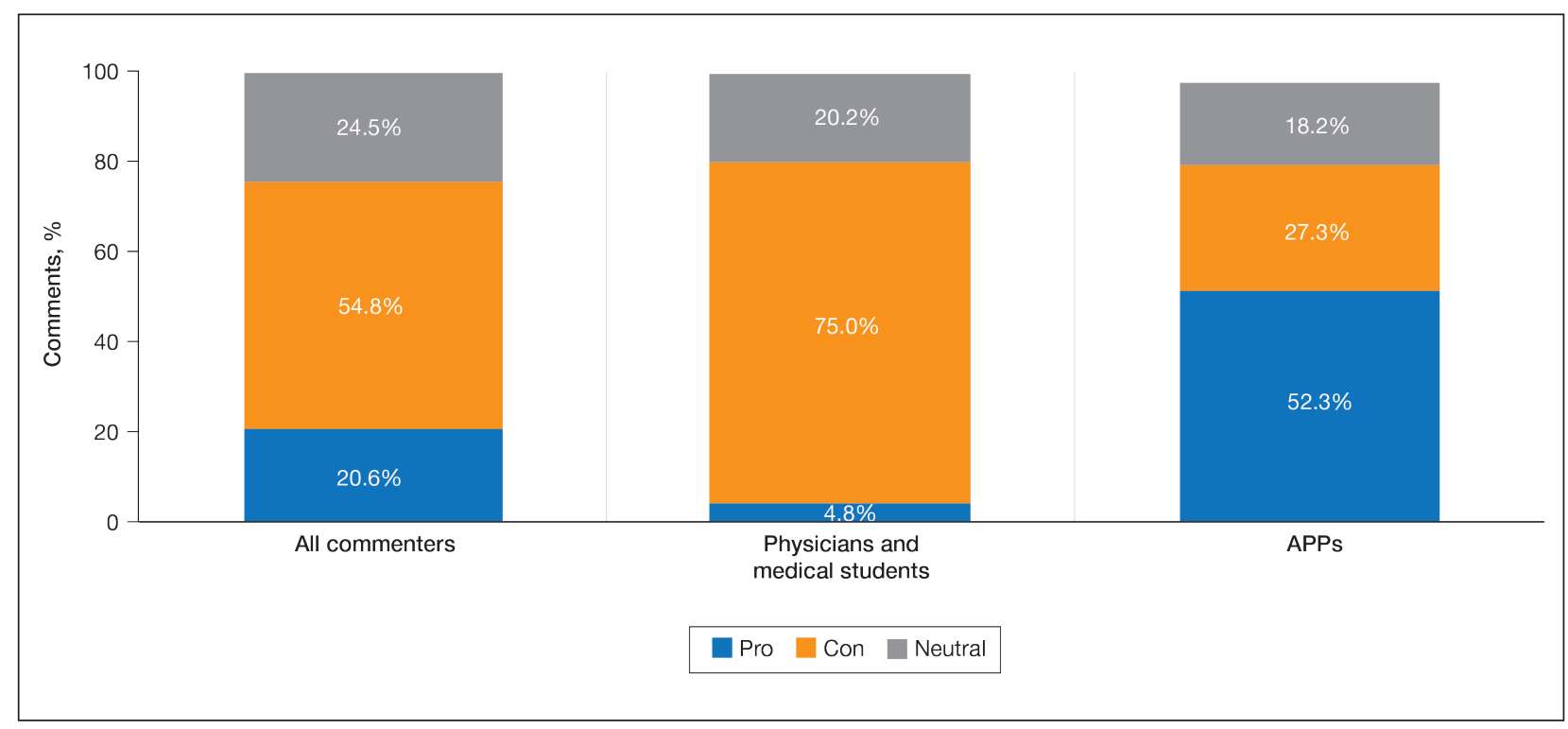

Support for executive order by provider type $(n=155)$. APP indicates advanced practice provider.

only $27.3 \%$ of APPs dissenting $(P<.0001)$. A similar percentage of both physicians/medical students and APPs remained neutral (20.2\% vs $18.2 \%)$. Commenters on Medscape were more likely to voice support for the executive order than those on Reddit (36.8\% vs $11.2 \%$; $P=.0002)$, likely due to the higher percentage of NP and PA comments on the former.

Overall, the most commonly discussed topic was provider reimbursement $(22.6 \%$ of all comments) (Table 2). Physicians and medical students were more likely to discuss physician expertise compared to APPs (32.1\% vs $4.5 \% ; P<.001)$. They also were more likely to raise concerns that the executive order would discourage future generations of physicians from pursuing medicine (15.5\% vs $0 \% ; P=.01)$. Advanced practice providers were more likely than physicians/medical students to comment on the breadth of NP and/or PAtraining (38.6\% vs $19.0 \% ; P=.02$ ). The eTable shows representative comments for each theme encountered.

A subgroup analysis of the comments written by physicians supporting the executive order $(n=4)$ and APPs disapproving of the order $(n=12)$ was performed to identify the dissenting opinions. Physicians who supported the order discussed the need for improved pay for equal work $(n=3)$, the competency of NP and PA training $(n=2)$, the ability of a practice to generate more profit from APPs $(n=1)$, and possible benefits of APPs providing primary care while MDs perform more specialized care $(n=1)$. Of the APPs who did not support the order, there were 4 PAs, 2 registered nurses, 2 NPs, 2 NP students, and 2 PA students. The most common themes discussed were the differences in APP education and training $(n=6)$, lack of desire for further responsibilities $(n=4)$, and the adequacy of the current scope of practice $(n=3)$.

\section{Comment}

President Trump's executive order follows a trend of decreasing required oversight of APPs; however, this study indicates that these policies would face pushback from many physicians. These results are consistent with a prior study that analyzed 309 comments on an article in The New York Times made by physicians, APPs, patients, and laypeople, in which $24.7 \%$ had mistrust of APPs and $14.9 \%$ had concerns over APP supervision compared to $9 \%$ who supported APP independent practice. ${ }^{7}$ It is clear that there is a serious divide in opinion that threatens to harm the existing collaborations between physicians and APPs.

Primary Care Coverage With APPs - In the comments analyzed in our study, supporters of the executive order argued that an increase in APPs practicing independently would provide much-needed primary care coverage to patients in underserved regions. However, APPs are instead well represented across most specialties, with a majority in dermatology. Of the 4 million procedures billed independently by APPs in 2012, 54.8\% were in the field of dermatology. ${ }^{8}$ The employment of APPs by dermatologists has grown from $28 \%$ of practices in 2005 to $46 \%$ in 2014, making this issue of particular importance to our field. ${ }^{9,10}$

Education and Training of APPS-In our analysis, many physicians cited concerns about the education and training of APPs. Dermatologists receive approximately 10,000 hours of training over the course of residency. Per the American Academy of Physician Assistants, PAs spend more than 2000 hours over a 26-month period on various clinical rotations, "with an emphasis on primary care." ${ }^{11}$ There are multiple routes to become an advanced practice $\mathrm{RN}$ with varying classroom and 
TABLE 2. Comment Theme by Profession ${ }^{\mathrm{a}}$

\begin{tabular}{|c|c|c|c|c|}
\hline Comment theme $^{a}$ & $\begin{array}{l}\text { All commenters, } \\
\mathrm{n}(\%)(\mathrm{n}=155)\end{array}$ & $\begin{array}{l}\text { Physicians and medical } \\
\text { students, } n(\%)(n=84)\end{array}$ & APPs, $n(\%)(n=43)^{b}$ & $P$ value \\
\hline Reimbursements & $35(22.6)$ & $16(19.0)$ & $12(27.3)$ & NS \\
\hline APP training & $34(21.9)$ & $16(19.0)$ & $17(38.6)$ & .02 \\
\hline Physician expertise & $31(20.0)$ & $27(32.1)$ & $2(4.5)$ & $<.001$ \\
\hline Quality of care provided & $22(14.2)$ & $10(11.9)$ & $10(22.7)$ & NS \\
\hline Independent midlevel practice & $22(14.2)$ & $11(13.1)$ & $11(25.0)$ & NS \\
\hline MD/DO and APP competition & $16(10.3)$ & $8(9.5)$ & $7(15.9)$ & NS \\
\hline Collaboration & $15(9.7)$ & $9(10.7)$ & $5(11.4)$ & NS \\
\hline Discourages future physicians & $14(9.0)$ & $13(15.5)$ & $0(0)$ & .01 \\
\hline Patient choice & $13(8.4)$ & $7(8.3)$ & $4(9.1)$ & NS \\
\hline Access to care & $11(7.1)$ & $5(6.0)$ & 4 (c & NS \\
\hline
\end{tabular}

Abbreviations: APP, advanced practice provider; MD, doctor of medicine; DO, doctor of osteopathic medicine; NS, not significant. apercentages do not total to $100 \%$, as commenters discussed more than 1 theme in certain comments.

${ }^{b}$ APPs include physician assistants, advanced practice registered nurses, physician assistant students, nursing students, and APPs not otherwise specified.

clinical requirements, with one pathway requiring a bachelor of science in nursing, followed by a master's degree requiring 500 to 700 hours of supervised clinical work. Although the Dermatology Nurses'Association and Society of Dermatology Physician Assistants (http://www .dermpa.org) provide online modules, annual conventions with training workshops, and short fellowship programs, neither have formal guidelines on minimum requirements to diagnose and treat dermatologic conditions. ${ }^{2}$ Despite the lack of formalized dermatologic training, APPs billed for $13.4 \%$ of all dermatology procedures submitted to Medicare in 2015. ${ }^{12}$

Quality of Patient Care-In our study, physicians also voiced concern over reduced quality of patient care. In a review of 33,647 skin cancer screening examinations, PAs biopsied an average of 39.4 skin lesions, while dermatologists biopsied an average of 25.4 skin lesions to diagnose 1 case of melanoma. ${ }^{13}$ In addition, nonphysician providers accounted for $37.9 \%$ of defendants in 174 legal cases related to injury from cutaneous laser surgery. ${ }^{14}$ Before further laws are enacted regarding the independent practice and billing by NPs and PAs in the field of dermatology, further research is needed to address patient outcomes and safety.

Limitations-This study was subject to several limitations. Because of a lack of other sources offering discussions on the topic, our sample size was limited. Self-identification of users presents a challenge, as an individual can pose as a physician or APP without validation of credentials. Although great care was taken to minimize bias, grouping comments into broad categories may misinterpret a poster's intentions. Furthermore, the data collected represent only a small proportion of the medical community_readers of Medscape and Reddit who have the motivation to create a user profile and post a comment rather than put their efforts into lobbying or contacting legislators. Those posting may have stronger political opinions or more poignant experiences than the general public. Although selection bias impacts the generalizability of our findings, this analysis allows for deeper insight into the beliefs of a vocal subset of the medical community who may not have the opportunity to present their opinions elsewhere.

\section{Conclusion}

Our analysis of the response to President Trump's executive order reveals that a rollout of these regulations would be met with strong opposition. On October 29, 2019, more than 100 professional organizations, including the American Medical Association and the American Academy of Dermatology, wrote a letter to the Secretary of Health and Human Services that eloquently echoed the sentiments of the physician commenters in this study: "Scope of practice of health care professionals should be based on standardized, adequate training and demonstrated competence in patient care, not politics. While all health care professionals share an important role in providing care to patients, their skillset is not interchangeable with that of a fully trained physician."15 The executive order would lead to a major shift in the current medical landscape, and as such, it is prudent that these concerns are addressed. 


\section{REFERENCES}

1. Balanced Budget Act of 1997, 42 USC \$1395x (1997). Accessed December 15, 2020. https://www.govinfo.gov/content/pkg/PLAW -105publ33/html/PLAW-105publ33.htm

2. State practice environment. American Association of Nurse Practitioners. Updated October 20, 2020. Accessed December 8, 2020. https://www.aanp.org/advocacy/state/state-practice-environment

3. Petterson SM, Liaw WR, Phillips RL Jr, et al. Projecting US primary care physician workforce needs: 2010-2015. Ann Fam Med. 2012;10:503-509.

4. United States, Executive Office of the President [Donald Trump]. Executive Order 13890: Protecting and Improving Medicare for Our Nation's Seniors. October 3, 2019. Fed Regist. 2019; 84:53573-53576.

5. Young KD. Trump executive order seeks proposals on Medicare pay for NPs, PAs. Medscape. Published October 3, 2019. Accessed December 8, 2020. https://www.medscape.com/viewarticle/919415

6. Trump seeks proposals on Medicare pay for NPs, PAs. Reddit. Accessed December 8, 2020. https://www.reddit.com/r/medicine/comments/ ddy03w/trump_seeks_proposals_on_medicare_pay_for_nps_pas/

7. Martin E, Huang WW, Strowd LC, et al. Public perception of ethical issues in dermatology: evidenced by New York Times commenters. Dermatol Surg. 2018;44:1571-1577.
8. Coldiron B, Ratnarathorn M. Scope of physician procedures independently billed by mid-level providers in the office setting. JAMA Dermatol. 2014;150:1153-1159.

9. Resneck JS Jr. Dermatology practice consolidation fueled by private equity investment: potential consequences for the specialty and patients. JAMA Dermatol. 2018;154:13-14.

10. Ehrlich A, Kostecki J, Olkaba H. Trends in dermatology practices and the implications for the workforce. J Am Acad Dermatol. 2017;77:746-752.

11. Become a PA. American Academy of Physician Assistants. Accessed December 8, 2020. https://www.aapa.org/career-central/become-a-pa/.

12. Zhang M, Zippin J, Kaffenberger B. Trends and scope of dermatology procedures billed by advanced practice professionals from 2012 through 2015. JAMA Dermatol. 2018;154:1040-1044.

13. Anderson AM, Matsumoto M, Saul MI, et al. Accuracy of skin cancer diagnosis of physician assistants compared with dermatologists in a large health care system. JAMA Dermatol. 2018;154:569-573.

14. Jalian HR, Jalian CA, Avram MM. Common causes of injury and legal action in laser surgery. JAMA Dermatol. 2013;149:188-193.

15. American Medical Association. Open letter to the Honorable Alex M. Azar II. Published October 29, 2019. Accessed December 11, 2020. https://searchlf.ama-assn.org/undefined/documentDownload ?uri=\%2Funstructured\%2Fbinary\%2Fletter\%2FLETTERS\%2F2019-10 -29-Final-Sign-on-re-10-3-Executive-Order.pdf 


\section{APPENDIX}

\section{eTABLE. Descriptive Comments by Theme ${ }^{a}$}

\begin{tabular}{|c|c|}
\hline Theme & Example \\
\hline Physician expertise & $\begin{array}{l}\text { "What is difficult to quantify and tends to be ignored is the level of critical thinking necessary to } \\
\text { develop a differential diagnosis. That list is most certainly limited by one's training." }\end{array}$ \\
\hline APP training & $\begin{array}{l}\text { "Nurse practitioners have over } 2000 \text { hours of training - both as an RN and NP . . Please } \\
\text { recognize [that] NPs who work in the field they were certified [in] have the same scope of } \\
\text { practice and ability as physicians, yet we have something physicians do not-training in the } \\
\text { science of nursing." }\end{array}$ \\
\hline $\begin{array}{l}\text { Discourages future generations } \\
\text { of physicians }\end{array}$ & $\begin{array}{l}\text { "Equalizing reimbursement destroys any incentive to be a physician and is [disrespectful] to } \\
\text { those of us who put in the time and effort to be physicians and incentivizes providers with a } \\
\text { quarter (or less) of the training." }\end{array}$ \\
\hline $\begin{array}{l}\text { Competition between } \\
\text { physicians and APPs }\end{array}$ & $\begin{array}{l}\text { "It wouldn't make sense for midlevels to support this. If pay is equalized between them and their } \\
\text { more educated and experienced colleagues (aka physicians), who do you think will get hired for } \\
\text { the job?" }\end{array}$ \\
\hline Access to care & $\begin{array}{l}\text { "Statewide regulations that force PAs/NPs to be affiliated with an MD/DO only limit patient } \\
\text { access to affordable care." }\end{array}$ \\
\hline Patient choice & $\begin{array}{l}\text { "There should be } 2 \text { insurance tiers; for example, } \$ 25 \text { copay for NP and } \$ 40 \text { for MD/DO. Let the } \\
\text { patient decide." }\end{array}$ \\
\hline $\begin{array}{l}\text { Patient outcomes and quality } \\
\text { of care }\end{array}$ & $\begin{array}{l}\text { "Time and time again (multiple published articles), NPs provide equivalent patient outcomes } \\
\text { when compare to their physician partners." }\end{array}$ \\
\hline Reimbursements & $\begin{array}{l}\text { "[APPs are] cheap labor, not equivalent labor. And the hospital, lab, path, and radiology are all } \\
\text { making money off those unnecessary tests. Midlevels are a bean counter's dream." }\end{array}$ \\
\hline Independent midlevel practice & $\begin{array}{l}\text { "After } 51 \text { years in health care, } 46 \text { years as an RN, and } 5 \text { 1/2 years as an NP, I do not need } \\
\text { oversight by a doctor. I do transfer to a doctor as needed." }\end{array}$ \\
\hline Collaboration & $\begin{array}{l}\text { mid-level profession is supposed to allow healthcare employees (MAs, nurses, } \\
\text { medics, etc) who are more academically motivated a chance to gain more training and help } \\
\text { physicians by doing more to offload their burden." }\end{array}$ \\
\hline
\end{tabular}

Abbreviations: APP, advanced practice provider; RN, registered nurse; NP, nurse practitioner; MD, doctor of medicine; DO, doctor of osteopathic medicine; MA, medical assistant.

${ }^{a}$ Comments were from Reddit and Medscape. 